\title{
Understanding medication adherence via lived experience: An experiential learning exercise for nursing students
}

\author{
John Brion \\ School of Nursing, Duke University, Durham, USA \\ Correspondence: J ohn Brion. Address: DUMC 3322, Durham, NC 27710. Telephone: 919-684-3865. Email: \\ john.brion@duke.edu
}

Received: November 8, 2011

Accepted: January 13, $2012 \quad$ Published: May 1, 2012

DOI : 10.5430/jnep.v2n2p133

URL:http://dx.doi.org/10.5430/jnep.v2n2p133

\begin{abstract}
Patients often receive a prescription with little instruction, which they often do not follow. These "non-compliant" patients are seen as being difficult or resistant. However, in reality these patients may truly be struggling to make a major behavioral change with little help or direction. Nurses' play a major role in the education and support of patients receiving new prescriptions, but too often nurses provide little more support and guidance than the medical provider. Unfortunately, some nurses also engage in the negative labeling of these patients. The purpose of the learning assignment described here was to provide pre-licensure nursing students an experiential learning opportunity to increase understanding and empathy for the difficulties often embedded in behavioral changes required when patients are asked to follow a new medical regimen. The framework for the assignment was Kolb’s Experiential Learning Model, which posits that lived experience allows for the transformation of theoretical or classroom knowledge into functional skills. The exercise made use of placebo medication and a 3 week course of treatment, during which time students kept written records of their adherence and feelings. Literature review, classroom discussion and a scholarly paper were used to help students process the experience. One focus of the post-experience processing was the application of newly gained knowledge in the development of nursing interventions to help with non-adherence.
\end{abstract}

\section{Key Words}

Adherence, Kolb, Experiential learning, placebo

Patients often receive a prescription with little more instruction than, "get this filled and take as ordered”. The patient may or may not follow those instructions; in fact, adherence rates of less than $50 \%$ are common in many patient populations. These patients are often labeled as non-compliant, difficult, or resistant, but they may just be struggling with making a major behavioral change without help or direction. The "difficult' or "non-compliant” patient is often seen as being lazy, disinterested, malingering or having a lack of motivation with regards to their healthcare. They are most definitely seen as unique and inferior to the "good" patients who take their medications; additionally they are seen as inferior to heath care staff. Nurses can, should and do play a major role in the education and support of patients receiving new prescriptions, but often nurses provide little more support and guidance than the medical provider and, many, unfortunately also engage in applying negative labels to these patients. The purpose of the learning assignment described here was to help pre-licensure 
students in an accelerated Bachelor of Science in Nursing (BSN) program have an opportunity to increase their understanding of and enhance their empathy for the difficulties that are often embedded in the behavioral changes required when patients are given a new prescription.

\section{Activity Description}

This experiential learning assignment was designed, implemented and evaluated with 65 students enrolled in the health promotion course of an accelerated BSN program. The goal of this assignment was to provide students with a "lived experience" of the health behavior change required of patients who are incorporating medication adherence into their lives. The assignment was developed using Kolb's experiential learning model as a guiding framework ${ }^{[6]}$. The Experiential Learning Model (ELM) is based on four elements operating in a cyclical fashion which equate to feeling, watching, thinking, and doing. Experiential education provides students with the opportunity to transform theoretical or classroom knowledge into functional skills. This method involves the process of establishing meaning from direct experience followed by reflection on the process ${ }^{[1]}$. According to Fowler ${ }^{[2]}$ experiential learning occurs as experience of sufficient quality is paired with meaningful reflection. If either the experience or the reflection is sub-standard then learning will be limited. There is agreement among the many models of experiential learning that learning seldom occurs unless the experience is assessed and reflected upon ${ }^{[3]}$. Experiential learning has been shown to enhance critical thinking, clinical reasoning, and empathy among students in healthcare programs ${ }^{[3-6]}$.

The assignment was first introduced through a discussion regarding the assumed characteristics of, and feelings students had about patients who do not take their medication as prescribed/directed by a health care provider. Students freely shared their thoughts, judgments and stereotypes regarding such patients and some intense discussion ensued. Care was taken at this initial stage of the project not to correct myths or misconceptions regarding patient compliance or to provide contemporary evidence in nursing or medical literature. Instead free flowing discussion was encouraged, regardless of the biases that may have been evident. Following the discussion each student was given a prescription bottle filled with 60 placebos (small breath mints). The bottle was labeled with precise instructions, for example: "take one pill 3 times per day by mouth for 20 days". Additionally, students were given verbal instructions (much like is done in a provider's office) to choose 3 time points during the day, 6-8 hours apart, for taking the "medications" over the next 3 weeks. As in a real medication situation, students were told there was a one hour window (30 minutes) on either side of the time they designated within which they could take the prescription. If the window was missed the medication was to be skipped. There were no additional restrictions for the "medication" (i.e. take with food, etc). The last component of the assignment was a requirement that students journal about the experience. This journaling was in two parts; first, students were required to record their adherence pattern, daily, in a small notebook that was provided. Second, they needed to write at least one reflection every 4 days about how they were feeling about the assignment and their level of participation. With each entry, students were to rate their level of adherence and whether their actual adherence was better or worse than they expected.

In addition to the instructions for taking the medication, there was one key rule for the assignment and it was that students could not quit. They had to continue trying to be adherent and to keep track of their attempts and their thoughts through the journaling component of the exercise. The parting words for the exercise were "just take your pills as prescribed, I will see you back in 3 weeks” no mention of the exercise was made by course faculty for the following 3 weeks.

This experiential learning exercise was designed to provide a lived experience of what it is like to be on a medication regimen. It is well understood that the system within which much healthcare is delivered is not as patient centered as would be optimal. There is much evidence that the system plays a significant role in non-adherence to medication and that healthcare providers can do a more adequate job helping their patients to become adherent ${ }^{[7,8]}$. This exercise was intended to provide an understanding of some difficulties faced by patients, via a lived experience, to increase insight and empathy among these future nurses. 


\section{Outcomes}

At the conclusion of the 3 week "prescription" period, students were asked to find an article about medication adherence in the literature and incorporate it into a paper about their experience. As part of the paper, they were to calculate their adherence rate by adding up all pills taken and dividing by 60 (total number of doses in their prescription) and compare their final (actual) result to what they had predicted at the start of the assignment. After submitting the paper a class session was held to discuss the exercise and its outcomes.

Six students (10\%) had perfect adherence. The overall class adherence rate was $63 \%$, reflecting a rate only slightly greater than what is seen across all disease and patient populations ${ }^{[9,10]}$. Class discussion and written materials (both their journals and written papers) revealed that most students struggled with many of the same barriers that are seen in the general population. Many students reported missing doses because they simply forgot, the main reason patients also miss doses. Forgetfulness for the students, just like in patient populations, increased with schedule changes (week-ends, family visits, working an off shift, variation between class and clinical days). Access to medications was another reason students cited for missing doses. Either they forgot pills at home or a few lost their prescription all together (which they had to "refill" thru the instructor, so they could continue). Another reason given for missing a dose was being engaged in social interaction and not wanting other people to see them taking a "pill". Some said they did not want people to think they were sick, others stated that they did not want to have to explain the activity to friends or family. This finding was similar to the fear of disclosure and stigma so often reported by actual patients in relation to missed doses. Some students reported getting tired of the taste of the "medication and finding that they just could not take another dose; very similar to the problems with side effects that often derail patient adherence. Finally, a lack of motivation was cited as a reason for missing doses (not wanting to get out of bed, pills in other room and did not want to get them, etc) which closely parallels reasons cited by the non-adherent patient population. Just as there are patients whose beliefs in alternative medicines and therapies hinder their willingness to follow a prescribed medication regimen, some students expressed reluctance to engage in such a non-holistic healing practice.

Many students developed effective coping techniques to help them remember doses. Much like highly adherent patients, students relied on a daily pill box, kept in a visible place, to help them remember their doses. Others reported carrying small vials of the pills in backpacks to reduce problems with access, setting phone or watch alarms to go off at dosing time, or writing reminder notes in highly visible places. Social support was reported as a major vehicle for remembering doses as people would "see others taking their pills" or be verbally reminded about not forgetting. A few students even reported borrowing a "pill" or two from friends when they had forgotten theirs, a behavior that is also seen in the patient setting.

The final component of the assignment was for students to take the insights learned from their personal experience, the article review and class discussion and use this information to design an intervention that could be used to help patients develop medication adherence plans. In class a plan was developed for some of the common reasons patients miss taking their medication. Students were encouraged to rely on the evidence of other studies, insight from their experience with the assignment, and the information classmates shared in class. Information from the student papers was used as the basis for a rich discussion examining the nurse's role in educating patients about the behavioral changes needed to incorporate medication adherence into their lives. Many helpful ideas that students had discovered for increasing their own adherence were used to build plans for different patients. Together the class discovered the why's and how's of medication adherence and how the nurse can use that knowledge to set the stage for patient success. As evidenced in class discussion and many student papers, the most impactful learning occurred as the students realized that the difference between provider and patient is often not that great. From this insight a new found feeling of compassion for patients and the barriers patients face regarding long-term medication adherence was verbalized by a majority of the class. The assignment was noted by both students and faculty as one of the most relevant assignments experienced in the program.

In summary, patient adherence to medication, across all diseases, is often less than needed to achieve successful clinical outcomes. Patients are often not given adequate instructions or supports related to new prescriptions and are often viewed 
negatively by healthcare staff when they fail to be totally adherent. This exercise was conducted to provide students with information about adherence through a carefully designed assignment that provided students with a "lived experience." The reflection papers and class comments suggest that students gained a more visceral understanding of the barriers and struggles associated with medication adherence. The knowledge gained from that lived experience, along with evidence from the literature, was quickly used to develop individualized nursing interventions to address those specific problems. Through the process the students were able to express empathy and caring for the patient as well as develop new solutions to support patient adherence.

The outcomes of this experience suggest that experiential learning is a useful and well accepted vehicle for increasing the critical thinking and clinical skills of nursing students. However, further research is needed to determine the extent to which this type of experiential learning impacts knowledge, critical thinking and the emotional intelligence of the learner. In addition, research into the long-term impact of experiential learning on future clinical practice is needed.

\section{References}

[1] Kolb, D.A.Experiential Learning: Experience as the Source of Learning and Development. Prentice Hall, Englewood Cliffs. 1984.

[2] Fowler, J.Experiential learning and its facilitation. Nurse Education Today. 2008; 28: 427-433. PMid:17881093 http://dx.doi.org/10.1016/j.nedt.2007.07.007

[3] Gibbs, M., Priest, H. Exploring the physical health needs of people with learning disabilities: Facilitation student engagement in learning, using Kolb’s experiential learning cycle. Nurse Education in Practice. 2010; 10: 115-118. PMid:19482549 http://dx.doi.org/10.1016/j.nepr.2009.04.005

[4] Benson, J., Witchger Hansen, A. Moving the classroom to the clinic: the experiences of occupational health students during a “living lab”. Occupational Therapy Health Care. 2007; 21(3): 79-91.

[5] Ganley, K., Mueller, K. Clinically relevant outcomes of immersion in service based experience for physical therapy students. Pediatric Physical Therapy. 2006; 18(1): 90-101. http://dx.doi.org/10.1097/00001577-200601810-00040

[6] Vanlaere, L., Coucke, T., Gastmans, C. Experiential learning of empathy in a care-ethics lab. Nurse Ethics. 2010; 17(3): 325-336. PMid:20444774 http://dx.doi.org/10.1177/0969733010361440

[7] National Institutes of Health. (2009) Clear Communication; An NIH Health literacy Initiative [Internet]. Available from: http://www.nih.gov/clearcommunication/healthliteracy.htm(Accessed January 9, 2012)

[8] Tarn, DM, Heritage, J, Paterniti, DA, et al. Physician communication when prescribing new medication. Archives of Internal Medicine. 2006; 166: 1855-1862. PMid:17000942 http://dx.doi.org/10.1001/archinte.166.17.1855

[9] DiMatteo, M. R., Giordani, P. J., Lepper, H. S., Croghan, T. W. Patient adherence and medical treatment outcomes: a meta-analysis. Medical Care. 2001; 40(9):794-811. PMid:12218770 http://dx.doi.org/10.1097/00005650-200209000-00009

[10] Vermeire, E., Hearnshaw, H., VanRoyen, P., Denekens, J. Patient adherence to treatment: three decades of research. A comprehensive review. Journal of Clinical Pharmacy and Therapeutics. 2001; 26: 331-342. PMid:11679023

http://dx.doi.org/10.1046/j.1365-2710.2001.00363.x 